\title{
Adding country resolution to EXIOBASE: impacts on land use embodied in trade
}

\author{
Eivind Lekve Bjelle ${ }^{1 *}\left(\mathbb{D}\right.$, Johannes Többen ${ }^{1}$, Konstantin Stadler ${ }^{1}$, Thomas Kastner ${ }^{2,3}$, Michaela C. Theurl², \\ Karl-Heinz Erb², Kjartan-Steen Olsen ${ }^{1}$, Kirsten S. Wiebe ${ }^{1,4}$ and Richard Wood ${ }^{1}$
}

*Correspondence:
eivind.bjelle@ntnu.no
1 Industrial Ecology
Programme, Department
of Energy and Process
Engineering, Norwegian
University of Science
and Technology (NTNU),
Trondheim, Norway
Full list of author information
is available at the end of the
article

${ }^{*}$ Correspondence: eivind.bjelle@ntnu.no 'Industrial Ecology Programme, Department of Energy and Process Engineering, Norwegian University of Science Trondheim, Norway article

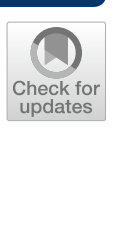

\begin{abstract}
Multiregional input-output (MRIO) databases are used to analyze the impact of resource use and environmental impacts along global supply chains. To accurately account for pressures and impacts that are highly concentrated in specific sectors or regions of the world, such as agricultural and land-use-related impacts, MRIO databases are being fueled by increasingly more detailed data. To date no MRIO database exists which couples a high level of harmonized sector detail with high country resolution. Currently available databases either aggregate minor countries into rest-of-the-world (WIOD and EXIOBASE 3), or the high country resolution is achieved at the cost of nonharmonized or lower sectoral detail (Eora, OECD-ICIO or the GTAP-MRIO). This aggregation can cause potentially significant differences in environmental and socioeconomic impact calculations. In this paper, we describe the development of an EXIOBASE 3 variant that expands regional coverage from 49 regions to 214 countries, while keeping the high and harmonized sectoral detail. We show the relevance of disaggregation for land-use accounting. Previous rest-of-the-world regions supply one-third of global land, which is used to produce a large range of different products under very different levels of productivity. We find that the aggregation of regions leads to a difference in the balance of land embodied in trade of up to $6 \%$ and a difference of land embodied in imports of up to $68 \%$ for individual countries and up to $600 \%$ for land-use-relevant sectors. Whilst the database can still be considered experimental, it is expected to increase the accuracy of estimates for environmental footprint studies of the original EXIOBASE countries, and provides the first estimates for the countries in the previous rest-of-the world.
\end{abstract}

Keywords: Multiregional input-output analysis, EXIOBASE, Land use embodied in trade, Country resolution, Rest-of-the-world regions, Regional aggregation, Land footprints

\section{Introduction}

From the early developments of domestic input-output analysis starting with Leontief (1936), the scope has broadened, both to account for trade relationships across economies (Leontief and Strout 1963) and to extend the framework to enable the attribution of social and environmental impacts, domestic and abroad, to economic activities (Leontief 1970; Miller and Blair 2009). Multiregional input-output (MRIO) models 
have been widely used in carbon footprint calculations as they provide an appropriate methodological framework for calculations at the national, international and global level (Wiedmann 2009b). In later years, MRIO applications have extended to a wide range of footprint analyses, such as material (Wiedmann et al. 2015; Ivanova et al. 2016; Bruckner et al. 2012; Wiebe et al. 2012), land (Ivanova et al. 2016; Steen-Olsen et al. 2012; Weinzettel et al. 2013), biodiversity (Verones et al. 2017; Lenzen et al. 2012; Wilting et al. 2017, Többen et al. 2018; Marques et al. 2019), labor (Alsamawi et al. 2014a; Simas et al. 2014), income inequality (Alsamawi et al. 2014b) and energy (Wiedmann 2009a; Owen et al. 2017).

The strength of MRIO analysis as a methodology for environmental impact assessment is its ability to trace the impacts of products through the whole supply chain and attribute the impacts at different stages of production to final consumers (Moran and Wood 2014). This enables MRIO analysis to trace increasingly fragmented international supply chains across primary, secondary and tertiary producers, to give a more complete picture of the impacts of final consumption of nations, in comparison to biophysical accounting methods purely based on physical data (Bruckner et al. 2015). A drawback of MRIO analysis in environmental impact studies is the lacking resolution to trace specific products and/or materials (Schaffartzik et al. 2015) or differentiate production technologies in detail. In addition, the efforts to harmonize sectoral and regional data and satellite accounts may require additional aggregation that can compromise the accuracy of environmental and socioeconomic results (Steen-Olsen et al. 2014; Lenzen 2011).

Today several global MRIO databases exist, such as Eora (Lenzen et al. 2013), WIOD (Timmer et al. 2015), GTAP-MRIO (Aguiar et al. 2016), the OECD-ICIO (Yamano and Webb 2018), and EXIOBASE (Tukker et al. 2013). Ideally, a global MRIO is as detailed as possible on both the product/industry resolution as well as on the number of explicitly represented countries. In addition, the ideal MRIO should be available as a consistent long and up-to-date time series and provide detailed socioeconomic and environmental extensions (Tukker and Dietzenbacher 2013). In order to have a consistent database between different world regions, MRIO developers necessarily need to deal with aggregations of extensions, regions and sectors into a standardized classification system (Lenzen 2011). Due to lack of easily available data for many countries, the approach sometimes used to reach global coverage is by estimating "rest-of-the world regions" (RoW), which typically consist of the remaining countries that are not explicitly covered in the database. In EXIOBASE and WIOD, RoW regions comprise over one-third of the world population and 33-44\% of global land use, and the aggregation of countries into regions can potentially underestimate impacts embodied in trade, in particular for highly localized pressures such as land use (Stadler et al. 2014).

Discrepancies in environmental impact results across MRIOs are well-documented (Giljum et al. 2019; Owen et al. 2014, 2016; Wieland et al. 2018) and hamper the policy uptake of MRIO results (Moran and Wood 2014; Peters 2007). The robustness of MRIO compared to other methods for estimating sector-specific environmental impacts such as for land use is disputed in the literature. For instance, Schaffartzik et al. (2015) compared biophysical methods and MRIO studies on land use and found a high correlation in regional results for various land use types per capita, except for a few outliers. On the other hand, when trying to interpret MRIO results in comparison to physical trade 
results, Kastner et al. (2014) found that China is a major net importer of cropland products and embodied cropland in MRIO studies, while physical trade analyses show the opposite. Hubacek and Feng (2016) argue that part of this discrepancy in results between analyses based on MRIO and physical trade balances can be attributed to the differencing system boundaries and conceptual differences, and thus the methods tackle different research questions. Bruckner et al. (2015) summarize the conceptual challenges of using MRIO for attributing land use impacts, especially where aggregation is performed due to lack of product detail (Weinzettel et al. 2014) and regional detail (Stadler et al. 2014). In terms of robustness of impact assessment results from MRIOs, Su et al. (2010) find that around 40 sectors are sufficient to avoid large uncertainties in $\mathrm{CO}_{2}$ emissions embodied in exports. Comparing the impacts embodied in exports by disaggregating the SUTs of EXIOBASE at a detail of 59 sectors versus 129 sectors, Wood et al. (2014) found differences in the order of maximum $5 \%$ for labor and compensation of employees, while $\mathrm{CO}_{2}$ impacts differed up to $50 \%$. Steen-Olsen et al. (2014) further investigated the effect of sector aggregation on $\mathrm{CO}_{2}$ multipliers $\left(\mathrm{kg} \mathrm{CO}^{2} / \$\right)$ in different MRIO databases. Similar to Wood et al. (2014), they found that aggregating sectors of different MRIOs to 17 sectors significantly changed the $\mathrm{CO}_{2}$ multipliers, and that the multiplier errors increased with increased sectoral detail in the original database. Similarity in economic input structures among sectors did not imply similarity in terms of emission profiles. This advocates for high sectoral detail despite the potentially much larger compilation effort when building MRIOs. This view is supported by Lenzen (2011) who proposed that aggregating environmental extensions to sectors is a large source of uncertainty as they can be highly heterogeneous. Consequently, Lenzen (2011) proposed disaggregating input-output structures to match the detail of the environmental extensions as the best option for estimating input-output multipliers and reducing uncertainties.

The effects of regional aggregation in MRIOs were studied by Bouwmeester and Oosterhaven (2013). Using EXIOBASE, they find large deviations in regional $\mathrm{CO}_{2}$ footprints (up to $22 \%$ ) and water use (up to $84 \%$ ) when aggregating 43 regions to four broad regions and one rest-of-the-world region. Su and Ang (2010) find that energy-related $\mathrm{CO}_{2}$ emissions are highly dependent on regional aggregation when using an MRIO of China, comparing China as a single region versus split into eight regions. Nevertheless, an earlier paper by Miller and Shao (1990) using an US MRIO model suggests that regional aggregation leads to smaller uncertainties than sectoral aggregation. In part, this is supported by de Koning et al. (2015) who found the aggregation of extensions to be more important than regional and sectoral aggregation for absolute material footprints. Although, due to a significant share of global material extraction in the global south, a more detailed regional coverage of this region in EXIOBASE has been called for by Wiebe et al. (2019). The study of regional aggregation effects due to the RoW aggregation by Stadler et al. (2014) showed that the RoW regions' share of global land use (33-44\% of the global total) are much larger than the equivalent share of global warming potential (17-22\%). Furthermore, Stadler et al. (2014) found that $38 \%$ of global land exports originate in the RoW regions, underlining the need for a higher country resolution to reduce uncertainties in estimating land use embodied in trade.

In terms of available MRIO databases, EXIOBASE has the highest consistent sector resolution of the available MRIO databases, but is limited in regional resolution. Eora 
has high country coverage and higher sector detail for some counties, but as the level of detail varies from region to region, this complicates the between-region comparison of impacts on a sectoral level. For example, Eora has only one sector aggregating all agricultural, forestry and fishing activities for most countries in the world. The GTAP-MRIO probably has the best compromise of sectoral resolution (57 sectors) and country (140 regions), but is currently not available as a time series, and has limited sectoral resolution outside the agricultural and food sectors. Ideally, there would be a MRIO database with high sector resolution, individual country coverage and a full time-series.

The aim of this paper is to describe the steps towards such an improved MRIO, by increasing the country resolution of EXIOBASE 3 to explicitly including all domestic economies registered in the UN main aggregates database (214 countries, see below).

We use this extended EXIOBASE (named EXIOBASE 3rx) to show the relevance of additional regional disaggregation to estimate land use embodied in trade. We study the degree of regional aggregation errors on both a regional and on a harmonized and detailed product level.

In the following method section, we describe the development of EXIOBASE 3rx and present its methodological building blocks, describe the processing of land use extensions, and the method for comparing the two databases with different regional resolution. In the result section, we present land footprints and explore the degree of regional aggregation errors for land use embodied in trade. To isolate the effect of regional aggregation on land use, we compare an EXIOBASE version where the MRIO structure is pre-aggregated (aggregation of IO data before calculation of coefficients and results), referred to from now on as the aggregated database, with EXIOBASE 3rx, where the land use results of the full detailed database are aggregated to 49 regions. The implication of this work is further picked up in the next section, where we discuss our results for both MRIO development and the use of MRIO for land use studies now and in the future.

\section{Methods}

\subsection{Building EXIOBASE 3rx}

The approach to building the monetary supply-use tables for EXIOBASE 3rx (Fig. 1) closely follows previous approaches establishing EXIOBASE 3 and EXIOBASE 2 (Wood et al. 2015, Stadler et al. 2018). Deviations from the EXIOBASE 3 workflow can be found in Additional file 1: S1. In EXIOBASE 3, the economic structures of 44 regions are available in the form of (aggregate) supply-use tables (SUTs). These SUTs are both disaggregated and balanced to product, industry, and trade data. From the SUTs, a trade-linking procedure (Wood et al. 2015) and application of an IO construct (Majeau-Bettez et al. 2014) is applied to obtain square MRIO tables. In order to estimate the SUTs for the RoW regions in EXIOBASE2 and 3, global average coefficient data was reconciled with product output, industry and trade data (see Stadler et al. (2014) for more information). EXIOBASE 3 adds top-level constraints of macroeconomic data to ensure consistency between regions and over time at a highly aggregate level.

EXIOBASE 3 had a strong European focus (28 EU member states, 16 major economies) and 5 RoW regions (RoW Asia and Pacific, RoW Europe, RoW Africa, RoW America, RoW Middle East). In this work, we extend the procedure used in estimating RoW 


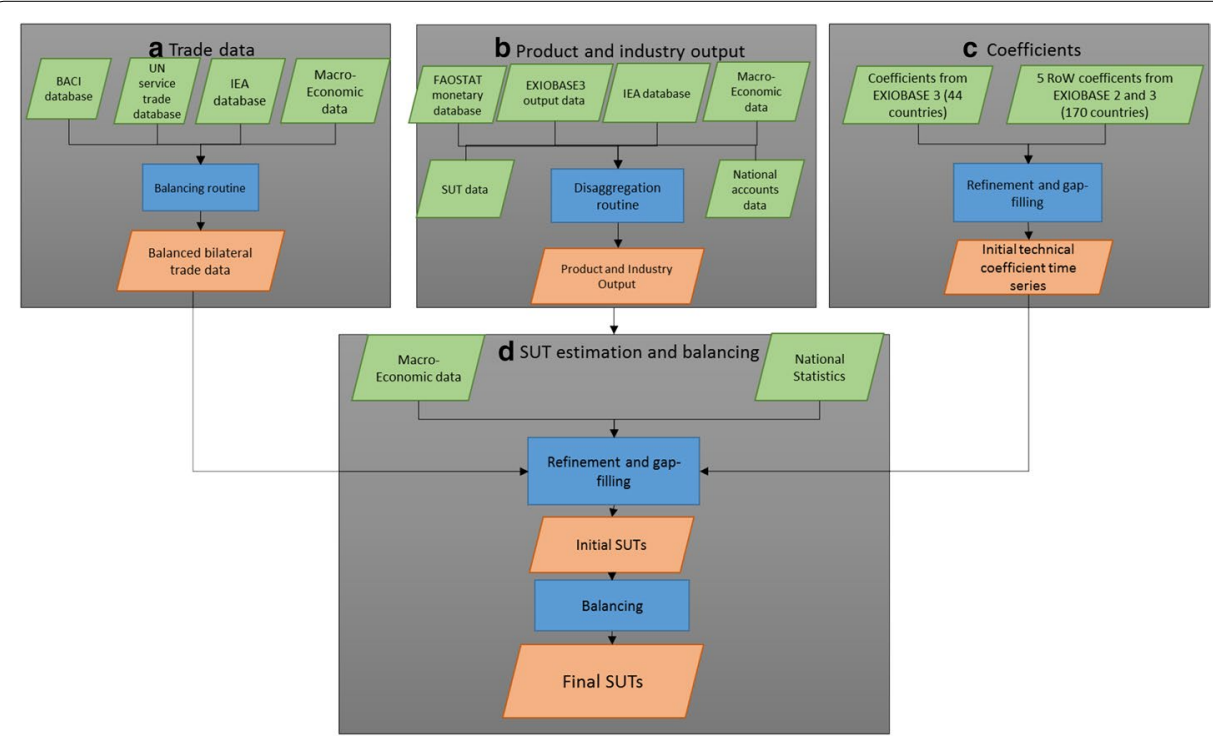

Fig. 1 EXIOBASE 3rx: compilation steps for monetary supply use tables. Approach based on figure in Stadler et al. (2018)

regions in EXIOBASE 3, but apply it to individual countries in order to expand the number of regions from originally 49 to 214 (Additional file 2). As SUT data are not commonly available for the countries in the RoW regions, we follow the regional approach where we use proxy data in the form of generic estimates of coefficients of the supply (i.e., market share relationships) and use matrices (intermediate use and final demand coefficients) to give an initial estimate of the product/industry transactions. The coefficients are then reconciled to globally balanced estimates of trade data, estimates of product outputs for every country and macroeconomic data on value added, taxes, exports, imports, final consumption and gross capital formation (for an overview of regional data sources, see Additional file 1: S2). The macroeconomic data serve as the top-level data towards which all the other data are balanced. The number of countries is based on the available macroeconomic data from the UN National Main Aggregates Database (United Nations 2018a). Additionally, we estimate land use extensions for all 214 countries (more info in Additional file 1: S11).

\subsection{Trade estimates and reconciliation}

In order to process the country-specific trade data, we combine data from three data sources when compiling the trade estimates. The BACI database is the main data source (balanced product trade data based on the UN Comtrade database, for more information see Gaulier and Zignago (2010)), while the UN services trade database (United Nations. 2018b) and the IEA database (International Energy Agency 2018) provide data for services and energy products/services, respectively. Re-exports are estimated in the same way as EXIOBASE 2 and 3 (based on SUT data for re-exports where available, and extrapolated based on Comtrade data).

After compiling the initial estimate of the trade data, this is reconciled against the top-level macroeconomic trade data in current price obtained from the UN National Accounts Main Aggregates Database. Here, we replace the quadratic programming 
approach with an information theoretical approach. We minimize cross-entropy (CE), also known as Kullback-Leibler Divergence (Kullback and Leibler 1951), between the final trade flows of product $i$ from country $r$ to country $s, p_{i}^{r s}$, and their initial estimate $q_{i}^{r s}$, subject to constraints requiring that total export and import values from the UN National Main Aggregates Database, $E X^{r}$ and $I M^{s}$, are met. In addition to the constraint that total exports by country and product are less than gross output, $x_{\text {max }_{\mathrm{i}}}^{r}$. For the general methodology, see Golan and Vogel (2000). As in Többen and Schröder (2018), we implement the computationally much more efficient unconstrained dual of the minimal cross-entropy problem. In the dual version, the cross-entropy model takes the form

$$
\begin{aligned}
\max _{\lambda} D=\sum^{r} & \lambda_{1}^{r} E X^{r}+\sum^{s} \lambda_{2}^{s} I M^{s}+\sum_{i}^{r}\left(\lambda_{\max _{i}}^{r}-\lambda_{\min _{i}}^{r} x_{\max _{i}}^{r}\right) \\
& -\sum_{i}^{r s} q_{i}^{r s} \exp \left\{\lambda_{1}^{r}+\lambda_{2}^{s}+\lambda_{\max _{i}}^{r}-\lambda_{\min _{i}}^{r}\right\} \\
& -\sum_{i}^{r} \lambda_{\max _{i}}^{r} x_{\max _{i}}^{r}-\sum_{i}^{r} \lambda_{\min _{i}}^{r} x_{\min _{i}}^{r}
\end{aligned}
$$

where $\lambda_{1}^{r}$ and $\lambda_{2}^{s}$ are Lagrangian multipliers referring to the equality constraints. Following the approach of Kazama and Tsujii (2005), the inequality constraints are formulated as lower and upper bounds with $\lambda_{\max _{i}}^{r}$ and $\lambda_{\min _{i}}^{r}$ being the Lagrangians and $x_{\max _{i}}^{r}$ and $x_{\min _{i}}^{r}$ being the bounds. In this application, the lower bounds are equal to zero, whereas the upper bounds are equal to gross output by country and product.

From the Lagrangians maximizing $D$, the final trade flows can be computed by

$$
p_{i}^{r s}=\frac{q_{i}^{r s} \exp \left\{\lambda_{1}^{r}+\lambda_{2}^{s}+\lambda_{\max _{i}}^{r}-\lambda_{\min _{i}}^{r}\right\}}{\sum_{i}^{r s} q_{i}^{r s} \exp \left\{\lambda_{1}^{r}+\lambda_{2}^{s}+\lambda_{\max _{i}}^{r}-\lambda_{\min _{i}}^{r}\right\}} .
$$

\subsection{Estimating product output}

Product output estimates were processed in EXIOBASE 3 (Stadler et al. 2018) and combines data from several national account databases, FAOSTAT (2014), IEA energy balances (IEA 2015) and product output from EXIOBASE 2 (for more information see Additional file 1: S1 and S9 in Stadler et al. (2018)). The main difference is that for EXIOBASE 3rx we process the raw data on an individual country level also for all former RoW countries. In the next step, these data sources served to disaggregate the UN macroeconomic industry output data (United Nations. 2018a), which consists of gross value added from seven aggregated industries. By applying a concordance matrix between the seven UN industries and the 163 EXIOBASE industries (Additional file 1: S3) and by assigning a quality index to the different data sources based on their closeness to raw data, the routine disaggregates the UN industry data. The disaggregation is based on the values in the chosen raw data source. The result is product output at the level of the 163 industries and 200 products of EXIOBASE. In general, this procedure should give reasonable estimates for agricultural, food and energy products, whilst missing detailed country-specific data on manufactured products and services. 


\subsection{Initial estimates of the input-output structure}

For the 44 countries that exist in EXIOBASE 3, the coefficients are used directly as initial estimates in EXIOBASE 3rx. For each of the 170 RoW countries, we use the coefficients from the respective RoW region from EXIOBASE 3. If EXIOBASE 3 coefficients caused balancing problems-such as conflicting constraints between the initial estimate of the SUT and the top-level macroeconomic data, we used EXIOBASE 2 coefficients instead.

\subsection{Balancing supply-use tables}

The monetary SUT balancing routine applies an algorithm similar to the approach in Stadler et al. (2018) using a quadratic programming target function. One important difference here is that, due to lack of data on a detailed country level, taxes, trade and transport margins are not estimated as explicit layers in our approach. Hence, our system is an MRIO in basic pricing only. The results are monetary SUTs estimated for every country and year independently for a time series from 1995 to 2015 for 214 countries. The balancing routine was unable to find a solution for a few countries, about $3.3 \%$ of all cases through the time series. See an overview in Additional file 1: S5 of the unbalanced countries.

\subsection{Converting from monetary SUTs to IO tables}

To go from individual SUTs to analytical IOTs, we stop at the step before creating fully detailed multiregional input-output tables (see Peters et al. 2011), and instead aim for trade-linked IOTs. This gives us the possibility to apply bilateral trade approaches rather than full MRIO approaches (Peters 2008, and see below). Due to the approach outlined above (balancing trade first, and not changing it in the SUT balancing), we ensure that the final SUTs are globally consistent (i.e., that imports and exports match for trading partners). The result is hence a fully trade-linked SUT system. In the final step, SUTs were converted to IO tables using the procedure described in EUROSTAT (2008). The industry technology construct is applied to deal with co-production. Using this approach, we avoid the problem of negative coefficients that could be faced when applying, e.g., the commodity technology construct (Jansen and Raa 1990). The choice of producing trade-linked IO tables rather than fully compiled MRIO tables (as per EXIOBASE3) was due to the significantly lower loading and running time, and does not constitute a loss of data (we had no additional data to inform the trade relationships). Normal desktop computers are not able to handle the memory requirements of a fully complied MRIO system of the size of EXIOBASE 3rx, but can easily handle the tradelinked system. Because of the trade proportionality assumption over the import use estimates, if a full MRIO system is desired, either the approach of Peters et al. (2011) could be followed if no memory constraints exist, or topological transformation of the data could be applied as explained in Rodrigues et al. (2016).

\subsection{Compiling the land use data}

To obtain land use data at the sectoral resolution of EXIOBASE, we followed a two-step procedure: First, we created spatially explicit maps for major land cover types based on publicly available state-of-the-art datasets. The data were harmonized following a closed-budget mapping approach (Erb et al. 2007), i.e., the sum of all layers will add up 
to $100 \%$ or the available land area for each specific grid cell. In a second step, we utilized information from census statistics (FAOSTAT) to further disaggregate the data to closely match the EXIOBASE sector classification (in table format). See Additional file 1: S11 for a detailed description of establishing the land use dataset.

The land use extensions comprise 207 countries, which cover most of the countries in EXIOBASE 3rx. For the remaining seven countries, mainly Island states like Palau and Nauru, we use the land area variable from FAOSTAT (2019) to estimate the land use accounts of the missing countries. We first choose a country (country A) with existing land use data and geographical proximity to the country with missing data (country B). Next, the land use extensions of country B are estimated by scaling the data of country A based on the land area variable of country B relative to that of country A. Next, we remap the land use data into EXIOBASE 3rx format. Here, we follow the same procedure as in EXIOBASE 3, and therefore refer the reader to S6 of Stadler et al. (2018). The resulting 40 land use extensions consist of land used by the EXIOBASE 3rx production sectors (F) and land directly allocated to households (F_hh).

\subsection{Estimating land footprints}

Due to the large size of EXIOBASE 3rx (e.g., the coefficient matrix (A) has 42,800 $\times 42,800$ data points), most of the arrays are saved in a sparse format in MATLAB to reduce disk storage requirements. The sparse format database for one year is approximately 60 megabytes.

We used the emissions embodied in bilateral trade (EEBT) approach (Peters 2007, 2008) to do land use calculations using EXIOBASE 3rx rather than calculating impacts from the MRIO system directly. The main difference is that we do not account for intermediate demand of imports that go to industries to produce exports. Hence, a limitation is that imports that are used for intermediate production, that later end up as exported goods are not accounted for. However, as we are studying aggregate land embodied in trade, and not that resulting from a particular final demand, the EEBT approach is suitable as discussed in Peters (2007). The basic principles of the EEBT approach are explained in S12. Stadler et al. (2014)'s additional information explains the EEBT approach in detail.

\subsection{Analyzing the effect of regional aggregation}

To enable comparison of the pre-aggregated database and EXIOBASE 3rx for land use results, we aggregate the inter-industry flow matrix $(\mathbf{Z})$, the final demand matrix $(\mathbf{Y})$, the total land use of production (F), and land directly allocated to households (F_hh) to 49 regions using a regional bridging (Additional file 2). Next, we calculate the coefficient matrix $(\mathbf{A})$ and the land use multipliers $(\mathbf{S})$ per monetary unit. We refer to this as the aggregated database from now on. Note that we do not compare land use results of EXIOBASE 3rx and EXIOBASE 3 directly as it would be difficult to distinguish the effect of regional disaggregation to effects arising from other changes (see Additional file 1: S1 for an overview of the differences in workflows between the databases). Two of the most prominent changes to the workflow are the mentioned updated trade processing and reconciliation, and re-processed and more detailed land use extensions. In addition, the land use dataset was newly established specifically for EXIOBASE 3rx. 
For comparing the land embodied in trade between the EXIOBASE 3rx and the aggregated database, we define the aggregation error as the sum of the absolute difference of the traded land in question:

$$
\epsilon=\sum_{s=1}^{n}\left(\left|T_{q, r, p_{\mathrm{EXIO} 3 \mathrm{rx}}}-T_{q, r, p_{\mathrm{Agg}}}\right|\right)
$$

where $T$ is a three-dimensional array of land embodied in imports or exports with dimensions imports/exports $(q)$ by trade partner $(r)$ by product $(p) . s$ corresponds to the summed-over dimension(s) and $n$ is the number of data points in the summed-over dimension(s). $n$ varies according to the type of aggregation error in question. We examine aggregation errors of imports and exports of products, between regions, and specific product-region combinations. Hence, for, e.g., the product aggregation error of imports, we sum over $q, r$-exporting and importing countries. Similarly, for the aggregation error of exports of specific goods originating in specific countries, we sum over $r$-importing countries. Note that we exclude intra-RoW trade in EXIOBASE 3rx aggregated to 49 regions for the sake of comparison with the aggregated database, where intra-RoW trade is part of domestic demand.

"Aggregation error" refers to the difference in results between those from one inputoutput table and those from a pure aggregation of the same input-output table prior to calculations (as per literature, e.g., Gibbons et al. (1982)). It must be noted that inputoutput tables are always estimates of actual transactions and the more disaggregated an input-output table is (especially in the case at hand where there is very poor statistical coverage of some countries) the higher the level of uncertainty of these transactions. Most literature (e.g., Lenzen (2011)) point to the benefit of disaggregation for reducing the uncertainty of footprint calculations, but we do not explore that here. As such, it must be remembered that uncertainty related to disaggregation, and the concept of aggregation error are related, but different concepts. We expect, but cannot measure whether the accuracy of our results will increase by disaggregating EXIOBASE3, whilst we can measure the aggregation error between the disaggregated database and a pure of aggregation of the same database.

Using Eq. 3 we define the aggregation error score $\epsilon_{s}$ as the aggregation error divided by the export/imports of the region, product or product-region combination in the 49 region version of EXIOBASE 3rx:

$$
\epsilon_{s}=\frac{\epsilon}{T_{q, r, p_{\mathrm{EXIO} \mathrm{rx}}}} .
$$

\section{Results}

The results of the construction process for EXIOBASE 3rx are available at https://doi. org/10.5281/zenodo.2654460. Country SUTs are available as well as IOTs and land extensions. Furthermore, in Additional file 3 we provide compiled production, consumption and trade-related results for land use. Here, we proceed with an analysis of these results, and the differences introduced by regional disaggregation. 
Table 1 Percentage of intra-RoW region exports for year 2015

\begin{tabular}{lrl}
\hline \% of exports within region & & $\begin{array}{l}\text { Rank } \\
\text { export } \\
\text { partners }\end{array}$ \\
\hline RoW Asia and Pacific & 22.2 & 1 \\
RoW Europe & 8.6 & 2 \\
RoW Middle East & 15.4 & 1 \\
RoW America & 26.2 & 1 \\
RoW Africa & 11.9 & 2
\end{tabular}

\subsection{Trade comparisons}

The added regional detail changes the trade structure of EXIOBASE 3rx compared to the aggregated database and EXIOBASE 3. In EXIOBASE 3, intra-RoW trade flows are treated as "domestic" flows, while they are treated as inter-country trade flows in EXIOBASE 3rx. In 2015 intra-RoW trade (as classified in EXIOBASE 3) is the largest or second largest export destination of each continental region (Table 1).

This has relevance to the regional disaggregation of EXIOBASE 3 for footprint analyses both for the countries within the RoW region and for the trade partners importing from the RoW region. In the former case a footprint resulting from a demand for an imported good from, e.g., Thailand to the Philippines would be treated as domestic in EXIOBASE 3 with the land use (or emission) intensity equal to the RoW region, while in EXIOBASE 3rx the footprint is treated as imports using the land use intensity of Thailand, which can lead to highly differing results as discussed in the introduction. In the latter case, a final demand of imports from a RoW region with destination in a region outside the RoW region will in both EXIOBASE 3 and EXIOBASE 3rx be treated as an import, but the emission intensity will differ. In EXIOBASE 3 the RoW land use intensity of production is used, while in EXIOBASE 3rx the land use intensity of production of the region now disaggregated from the RoW region forms the basis of the footprint.

\subsection{Land footprints}

The cropland footprints per capita for all 214 regions in 2015 are presented in Fig. 2 (see Additional file 1: S10 for figures on other land use types and Additional file 3 for per capita footprints for individual land use types and aggregated across all land use types). Monaco has the largest cropland footprint per capita $\left(24,700 \mathrm{~m}^{2} / \mathrm{cap}\right)$ followed by Luxembourg (19,100 $\left.\mathrm{m}^{2} / \mathrm{cap}\right)$ and the United Arab Emirates (9 $\left.100 \mathrm{~m}^{2} / \mathrm{cap}\right)$. The lowest footprints are found in Timor-Leste ( $\left.257 \mathrm{~m}^{2} / \mathrm{cap}\right)$, Bermuda (336 $\left.\mathrm{m}^{2} / \mathrm{cap}\right)$, and Zanzibar (353 $\left.\mathrm{m}^{2} / \mathrm{cap}\right)$. Large economies such as the United States $\left(3620 \mathrm{~m}^{2} / \mathrm{cap}\right)$, Russia (5250 m²/cap), Germany ( $3260 \mathrm{~m}^{2} / \mathrm{cap}$ ) and France (3330 $\left.\mathrm{m}^{2} / \mathrm{cap}\right)$ have cropland footprints per capita well above the global average of $2130 \mathrm{~m}^{2} / \mathrm{cap}$, while those of China (1710 $\left.\mathrm{m}^{2} / \mathrm{cap}\right)$ and India $\left(1260 \mathrm{~m}^{2} / \mathrm{cap}\right)$ are below the global average. In general, the highest per capita footprints are in Europe, the Middle East, Eastern and Northwestern parts of Asia and a few scattered African countries. The import share of total cropland consumed highly varies between countries (see Additional file 3 ). With countries in the Middle East, some island states and Eastern parts of Asia, having import shares of 100\%, while particularly several African countries import less than $5 \%$ of the land area needed 


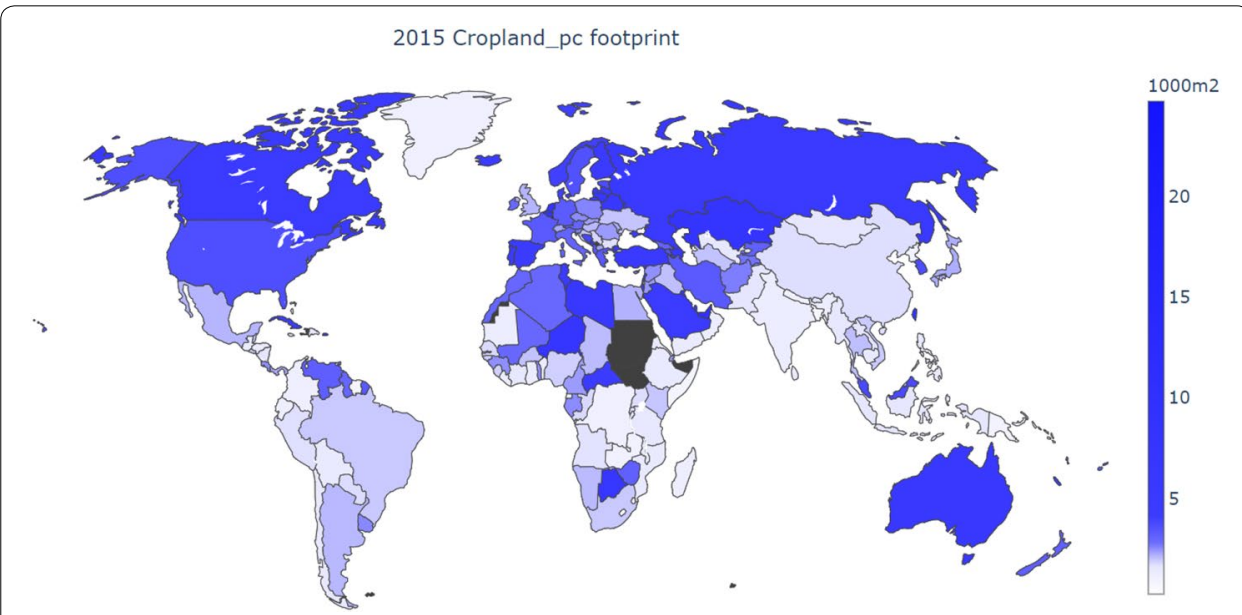

Fig. 2 Map of cropland footprints per capita for year 2015 for 214 countries. Unbalanced countries in dark gray (Comoros, Haiti, Liechtenstein, South Sudan and Sudan)

to satisfy their cropland consumption. For EXIOBASE 3rx, the global import share of cropland consumption increased from 20.9\% in 1995 to $42.7 \%$ in 2015.

The global consumption-based per capita forest footprint is $3650 \mathrm{~m}^{2}$, with the largest values found for Finland $\left(68,100 \mathrm{~m}^{2}\right)$ and New Caledonia $\left(49,300 \mathrm{~m}^{2}\right)$, and smallest for Palestine $\left(82.4 \mathrm{~m}^{2}\right)$ and Yemen $\left(146 \mathrm{~m}^{2}\right)$. The global imported share of total forest consumption is $36.0 \%$. The global per capita grazing land footprint is $3650 \mathrm{~m}^{2}$ with an import share of $21.3 \%$. Mongolia $\left(1,34,000 \mathrm{~m}^{2}\right)$ and Botswana $\left(97,500 \mathrm{~m}^{2}\right)$ have the highest values and North Korea $\left(99.5 \mathrm{~m}^{2}\right)$ and Bangladesh $\left(113 \mathrm{~m}^{2}\right)$ have the lowest per capita values. The British Virgin Islands $\left(1650 \mathrm{~m}^{2}\right)$ and Australia $\left(1500 \mathrm{~m}^{2}\right)$ have the highest per capita infrastructure footprints, well above the global average of $185 \mathrm{~m}^{2}$. The total land use summed across all land types has grown by $1.6 \%$ from 1995 to 2015 . On a per capita basis, global land use has decreased from $15600 \mathrm{~m}^{2}$ ha/capita to $12300 \mathrm{~m}^{2} /$ capita (27\%) from 1995 to 2015. This is driven by a moderate decrease in consumption-based land use in populous countries such as India, Brazil and the United States, and a stronger decrease in several African countries. Increases in countries such as China, Germany and the Netherlands partly offset the effect.

Overall there is a factor of 2.20 increase of land embodied in trade from 1995 to 2015. This increase is driven by a growth in exports from geographically large countries such as Russia, Australia and Brazil. China has largely single-handedly driven the global increase in imported land, from $2.3 \%$ of the global total in 1995 to $27.4 \%$ in 2015 . At the same time, the global share of imported land has decreased particularly for Japan (9.5\% in 1995 and 3.6\% in 2015) and the United States (11.5\% in 1995 and 8.4\% in 2015).

\subsection{Comparison of regional disaggregation}

EXIOBASE 3rx shows global land embodied in trade as $25.8 \%$ of global land use, compared to $24.2 \%$ in the aggregated database (Table 2) (For equivalent results for all countries in EXIOBASE 3rx, see Additional file 1: S13.) Comparing country-specific trade balances of land for the databases, there is consistency in which countries are net 







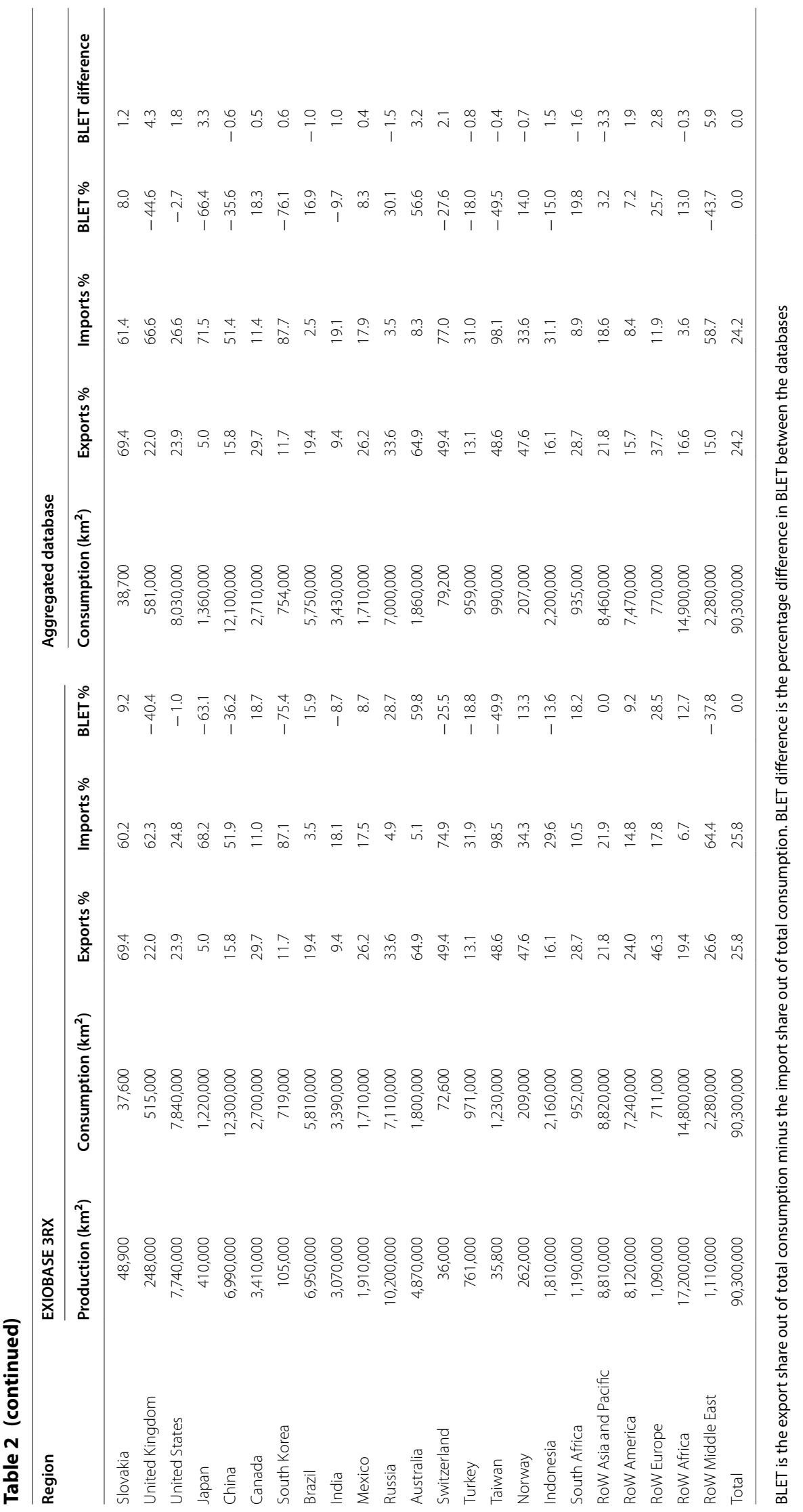


importers and exporters, but there is a difference of up to $5.9 \%$ in the balance of land embodied in trade between the databases.

The top 20 products (global aggregation of results across all countries) ranked according to aggregation error of land embodied in imports are displayed in Table 3. Remembering that the impacts embodied in imports originating in the non-RoW regions are identical in the aggregated and disaggregated database, these results reflect the effect of disaggregation purely of the EXIOBASE 3 RoW regions. The land embodied in imports associated with "Products of forestry, logging and related services (02)" is the single largest product group, with $66,10,000 \mathrm{~km}^{2}$ or $30.2 \%$ of total global land use embodied in imports. This product group is somewhat susceptible to regional aggregation error, with a summed difference between the aggregated and disaggregated database of $6,60,000 \mathrm{~km}^{2}$ or $19.4 \%$ of the total aggregation error observed between the models. In contrast, for "Meat animals nec" and "Hotel and restaurant services (05) "the share of land use embodied in exports is only in the range of $1-2 \%$, but the aggregation error of the product relative to the flow (shown by the "error score") is much higher at $64 \%$ and $95 \%$ of the value of the estimated flow, respectively. This suggests a large degree of uncertainty due to regional aggregation in the aggregated database. The last column of Table 3 shows that the aggregation can change the value of the flow by a factor of over five ("Copper ores and Concentrates") where the value in the aggregated database is $17 \%$ of the corresponding value in EXIOBASE 3rx.

The aggregation error for land embodied in imports for regions sorted by regional error score (Table 4) shows that the countries with the largest scores, such as Australia and Malta, have a low share of global imports, although the net effect of the aggregation error for the countries is significant. Countries with a low import share out of total consumption of land, such as Russia, Brazil and Australia (Table 2) have the largest aggregation errors. In addition, these countries stand out with a high proportion of land originating in EXIOBASE 3 RoW regions. A large share of the regional aggregation error is centered in Asia due to Taiwan and Japan having relatively larger aggregation error shares than land import shares, combined with China dominating land imports (although the aggregation error is relatively lower).

Digging deeper into the land embodied in imports by also showing the traded product (Additional file 1: Table S1), we find that the six largest product- and regionspecific aggregation errors are due to imports for Taiwan, China and India. Together, they make up about $19 \%$ of global aggregation error of land embodied in imports. Asian countries dominate the top 20 list. We also notice that certain items, such as imports of "Hotel and restaurant services (55)" to China and "Meat animals nec" to Japan have significant aggregation error scores. The net effect of the aggregation can change results by up to an order of magnitude ("Chinese imports of Hotel and restaurant services (55)").

By also including the origin region of the imported good, the concentration of the aggregation error around Asian regions and "Products of forestry, logging and related services (02)" becomes even more apparent (Additional file 1: S8). The total global aggregation error is concentrated on a few flows, with the top 20 contributors to the error summing up to $25 \%$ of the global total error. 12 of the top 20 flows are imports originating in RoW Asia. 


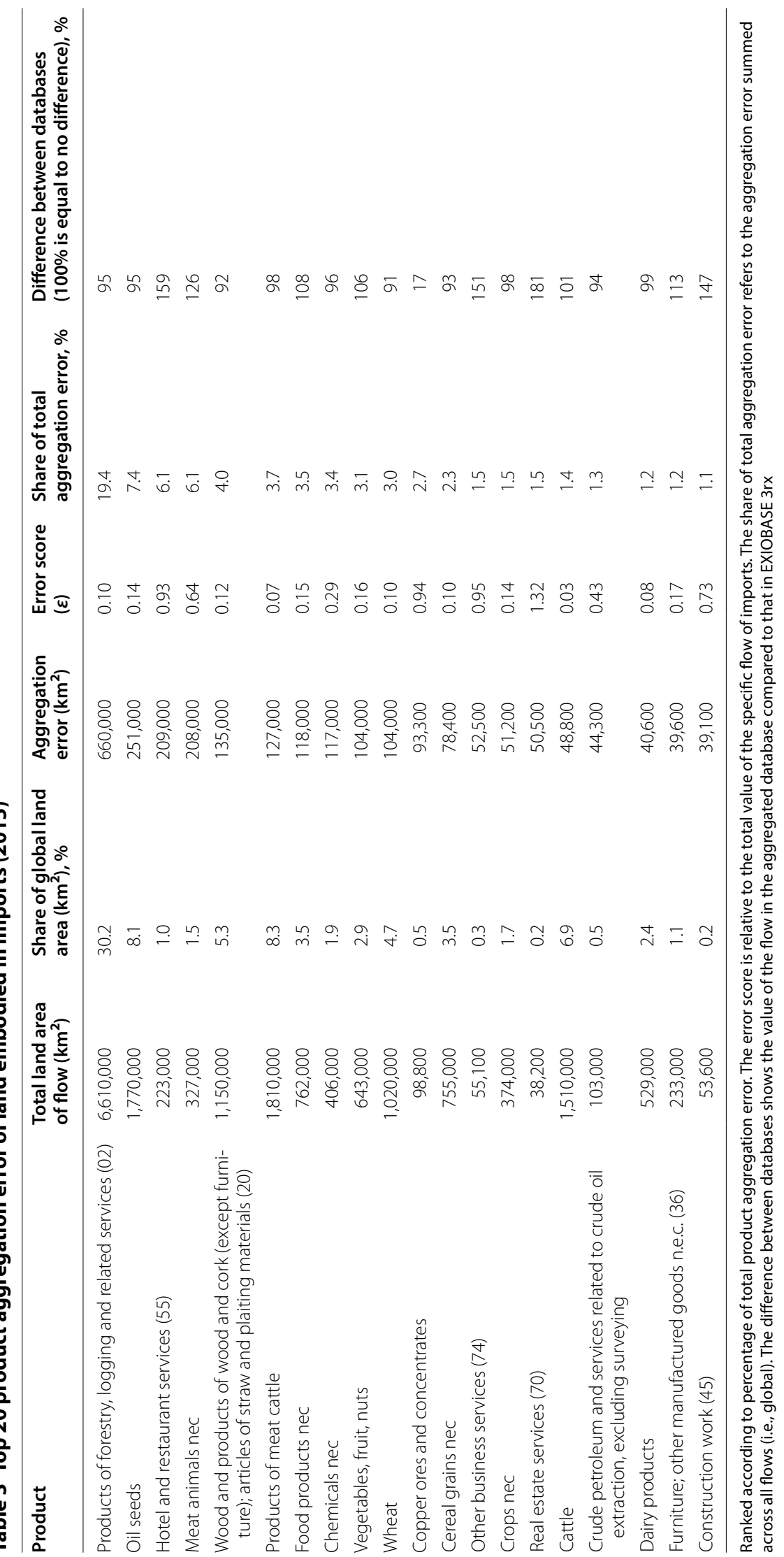


Table 4 Land embodied in imports and aggregation error of 49 regions (2015)

\begin{tabular}{|c|c|c|c|c|c|c|}
\hline Region & $\begin{array}{l}\text { Total land area } \\
\text { of flow }\left(\mathrm{km}^{2}\right)\end{array}$ & $\begin{array}{l}\text { Share of global } \\
\text { land area } \\
\left(\mathrm{km}^{2}\right), \%\end{array}$ & $\begin{array}{l}\text { Aggregation } \\
\text { error }\left(\mathrm{km}^{2}\right)\end{array}$ & Error score $(\varepsilon)$ & $\begin{array}{l}\text { Share of total } \\
\text { aggregation } \\
\text { error, \% }\end{array}$ & $\begin{array}{l}\text { Difference } \\
\text { between databases } \\
\text { (100 is equal } \\
\text { to no difference), \% }\end{array}$ \\
\hline $\mathrm{AU}$ & 92,300 & 0.4 & 67,400 & 0.73 & 2.0 & 168 \\
\hline MT & 3620 & 0.0 & 2050 & 0.57 & 0.1 & 141 \\
\hline BR & 203,000 & 0.9 & 83,100 & 0.41 & 2.4 & 70 \\
\hline RU & 350,000 & 1.6 & 143,000 & 0.41 & 4.2 & 69 \\
\hline$F R$ & 442,000 & 2.0 & 161,000 & 0.37 & 4.7 & 95 \\
\hline ZA & 99,900 & 0.5 & 35,600 & 0.36 & 1.0 & 84 \\
\hline $\mathrm{CH}$ & 54,400 & 0.2 & 18,000 & 0.33 & 0.5 & 112 \\
\hline GB & 321,000 & 1.5 & 100,000 & 0.31 & 2.9 & 121 \\
\hline $\mathrm{HR}$ & 10,000 & 0.0 & 3010 & 0.30 & 0.1 & 107 \\
\hline IN & 614,000 & 2.8 & 183,000 & 0.30 & 5.4 & 107 \\
\hline ES & 217,000 & 1.0 & 63,400 & 0.29 & 1.9 & 113 \\
\hline RO & 32,300 & 0.1 & 9200 & 0.28 & 0.3 & 108 \\
\hline PT & 127,000 & 0.6 & 34,900 & 0.27 & 1.0 & 87 \\
\hline LU & 26,200 & 0.1 & 7030 & 0.27 & 0.2 & 99 \\
\hline BE & 217,000 & 1.0 & 57,600 & 0.27 & 1.7 & 87 \\
\hline SI & 14,200 & 0.1 & 3740 & 0.26 & 0.1 & 91 \\
\hline GR & 48,600 & 0.2 & 12,700 & 0.26 & 0.4 & 99 \\
\hline TW & $1,210,000$ & 5.6 & 315,000 & 0.26 & 9.2 & 80 \\
\hline NO & 71,700 & 0.3 & 16,900 & 0.24 & 0.5 & 97 \\
\hline TR & 310,000 & 1.4 & 72,500 & 0.23 & 2.1 & 96 \\
\hline DK & 53,200 & 0.2 & 12,200 & 0.23 & 0.4 & 102 \\
\hline LT & 29,900 & 0.1 & 6730 & 0.23 & 0.2 & 84 \\
\hline $\mathrm{NL}$ & 325,000 & 1.5 & 71,600 & 0.22 & 2.1 & 111 \\
\hline IT & 351,000 & 1.6 & 75,200 & 0.21 & 2.2 & 99 \\
\hline DE & 573,000 & 2.6 & 112,000 & 0.19 & 3.3 & 103 \\
\hline$J P$ & 834,000 & 3.8 & 160,000 & 0.19 & 4.7 & 117 \\
\hline IE & 45,900 & 0.2 & 7890 & 0.17 & 0.2 & 110 \\
\hline $\mathrm{HU}$ & 30,300 & 0.1 & 4930 & 0.16 & 0.1 & 97 \\
\hline WM & $1,350,000$ & 6.2 & 213,000 & 0.16 & 6.2 & 99 \\
\hline BG & 14,600 & 0.1 & 2210 & 0.15 & 0.1 & 108 \\
\hline$P L$ & 114,000 & 0.5 & 16,800 & 0.15 & 0.5 & 97 \\
\hline WE & 100,000 & 0.5 & 14,600 & 0.15 & 0.4 & 92 \\
\hline CY & 4460 & 0.0 & 636 & 0.14 & 0.0 & 106 \\
\hline AT & 78,000 & 0.4 & 10,900 & 0.14 & 0.3 & 101 \\
\hline US & $1,950,000$ & 8.9 & 252,000 & 0.13 & 7.4 & 110 \\
\hline KR & 626,000 & 2.9 & 76,700 & 0.12 & 2.3 & 106 \\
\hline LV & 30,200 & 0.1 & 3530 & 0.12 & 0.1 & 90 \\
\hline ID & 639,000 & 2.9 & 73,800 & 0.12 & 2.2 & 107 \\
\hline$C Z$ & 48,000 & 0.2 & 5400 & 0.11 & 0.2 & 102 \\
\hline $\mathrm{CN}$ & $6,360,000$ & 29.1 & 677,000 & 0.11 & 19.8 & 98 \\
\hline EE & 11,500 & 0.1 & 1180 & 0.10 & 0.0 & 98 \\
\hline SK & 22,600 & 0.1 & 2280 & 0.10 & 0.1 & 105 \\
\hline SE & 182,000 & 0.8 & 16,400 & 0.09 & 0.5 & 104 \\
\hline WF & 530,000 & 2.4 & 46,700 & 0.09 & 1.4 & 100 \\
\hline CA & 296,000 & 1.4 & 23,700 & 0.08 & 0.7 & 105 \\
\hline WA & $1,580,000$ & 7.3 & 100,000 & 0.06 & 2.9 & 100 \\
\hline MX & 298,000 & 1.4 & 14,200 & 0.05 & 0.4 & 103 \\
\hline $\mathrm{Fl}$ & 284,000 & 1.3 & 5690 & 0.02 & 0.2 & 100 \\
\hline WL & 622,000 & 2.8 & 12,200 & 0.02 & 0.4 & 101 \\
\hline
\end{tabular}


Table 4 (continued)

Sorted by aggregation error score. The error score is relative to the total value of the specific flow of imports. The share of total aggregation error refers to the aggregation error summed across all flows (i.e., global). The difference between databases shows the value of the flow in the aggregated database compared to that in EXIOBASE 3rx

\section{Discussion}

\subsection{Hotspots for aggregation errors of land embodied in trade}

Countries such as China show sharp trends of rapid increases in imports in the later years, and as such also become the main importers of traded land (see Additional file 3). Results show that there is a need for the integration and calculation of a high level of regional detail in these countries' trade partners to avoid regional aggregation errors. We find that the import aggregation errors of Asian countries such as China, India, Taiwan and Japan make up a large share of the global total error (Table 4). Although RoW Asia contributes to only $7.2 \%$ of global exported land, the contribution to the export aggregation error is $47.9 \%$ (Additional file 1: S8).

The effect of regional aggregation on land embodied in trade by products shows a large concentration of both land embodied in trade and aggregation errors around a handful of products (Table 3 ). The products are mostly part of the forestry and agricultural sectors, with a few outliers in the service sectors such as "Hotels and restaurant services (55)", "Other business services (74)" and "Real estate services (70)". These outliers are characterized by low shares of total land embodied in trade, but relatively larger shares of aggregation errors. The same is the case for some of the more disparate products groups (those in the not elsewhere classified groups). These later results indicate the need for also more detailed sectoral resolution (see below).

The regions and products prone to aggregation errors depend on the year chosen. We chose to present results for 2015 in this paper, as this is the most recently available data in EXIOBASE 3rx. A look into the aggregation errors summed together across the whole time series (Additional file 1: S8, and S9 for 2015) reveals that 37.4\% of the export aggregation error now comes from RoW Africa (27.1\% in 2015), while RoW Asia is responsible for $45.6 \%$ of the global total (47.9\% in 2015). The import aggregation errors for regions show the same trends, except for Portugal that now ranks third when sorting by regions. The products most heavily affected by the aggregation throughout the time series show similar trends to the equivalent 2015 result, but even more concentrated around products of forestry, logging and related services (02) which accounts for $25.9 \%$ of the total aggregation error across the full time series (19.4\% in 2015). Including the origin and destination of imports reveals that the top four flows, making up $12 \%$ of the total aggregation error, are "Products of forestry, logging and related services (02)" from RoW Africa to China, Portugal, India and France.

Compared to other works, Kastner et al. (2014) found that MRIO studies on cropland embodied in Chinese trade diverged from studies using other methods. We find that China's balance of land embodied in trade for all land types (Table 2) did not significantly differ between the two levels of regional aggregation. Despite not finding an aggregation effect, we find a significant change in China's balance of cropland embodied in trade from 1995 to 2015 (Additional file 1: S6). From 1995 to 2000 China was a net exporter of cropland, while from 2001 to 2015 there is a shift to becoming a net importer 
and increasingly so as we approach present time. Although our results use monetary values for the trade allocation, while studies using other methods typically use physical properties, the time trend we find should be interesting for future research looking at the deviations in results between methods.

Given that a few countries import a large share of globally traded land, we find it is particularly important to have their trading partners represented as individual regions in MRIOs. Similarly, key exporting regions not currently included, such as Argentina, should be represented, and large countries (such as China) can even be split into subregions as suggested by Su and Ang (2010) to minimize aggregation errors.

\subsection{Challenges and limitations}

The inclusion of 214 countries in a single database comes with a trade-off in terms of raw data availability and uncertainty. Whilst country-specific land use, production, and trade data are used (for an overview of the regional data availability in the raw data, see Additional file 1: S2), a lot of data estimation is undertaken, especially for the countries not originally in the EXIOBASE dataset. For the 44 countries originally in the EXIOBASE 3 dataset, it would be expected that the additional disaggregation of the rest-of-theworld regions would improve accuracy. However, for the remaining countries, it must be expected that the uncertainty of individual country estimates are high. Especially when disaggregating small (and trade-exposed) countries the expectation of accuracy is low. It is common in all input-output studies (and all statistical data) to find a declining relationship between accuracy and volume (whether expressed as GDP, output, or key coefficients) (see for example (Lenzen et al. 2010, Karstensen et al. 2015, Wood et al. 2019)) for one reason because of the laws of error propagation (Imbeault-Tétreault et al. 2013). Whilst further work could see the replacement of generic data with more country-specific data, it is still likely that the uncertainty levels of individual countries in the disaggregated database will be high, and it is anticipated that the further development of single-country national account consistent procedures are further developed in order to undertake county specific analysis (see, e.g., Edens et al. (2015); Palm et al. (2019); Hambÿe et al. (2018)).

In terms of empirical validation of results as presented, there are sudden jumps in per capita land footprint results, particularly for small economies such as Aruba, San Marino, Bermuda, the Cayman Islands and the British Virgin Islands (as can be seen in Additional file 1: S6). In addition to being small economies, several of these countries heavily rely on imports with import shares in the range of 95-98\% of the total consumption-based land footprints, except for the British Virgin Islands and the Cayman Islands where this value is $43.0 \%$ and $50.7 \%$, respectively (see Additional file 1: S13). When there is a jump in land footprint, we do note that that there are sudden changes in the import structure for the specific years (see https://oec.world/en/ (Simoes and Hidalgo 2011) for a visualization of trade data). Aruba has a drastic increase in imports of cattle from Sudan (2010), Bermuda and the British Virgin Islands import crude petroleum from Kazakhstan (2000-2003), San Marino imports raw fur skins from Russia (2006), while the Cayman Islands import soybeans from Paraguay (2001-2007). Drastic increases in imports of these specific products from countries with high use of land area per monetary output, combined with high import shares drastically change the per capita 
footprint of these countries using the EEBT approach. The EEBT approach however, does not allow us to determine whether these imports are used for domestic consumption, or intermediate production that is later used for exports and therefore should not be counted in that country's consumption-based footprints.

In terms of data reconciliation issues, most of the challenges in building EXIOBASE 3rx were related to the SUT balancing where there were contradictions between the initial estimates and the macroeconomic data. Several of these issues were resolved by changing options in the balancing routine that increased the accepted level of deviation (which was set to a cap in the balancing) from the initial estimated SUTs. If this did not work, we used initial technical coefficient estimates from EXIOBASE 2. In several of the remaining unbalanced cases (Additional file 1: S5), the issue is negative value added from the macroeconomic data specifically for International Standard Industrial Classification C and E from the UN National Main Aggregates Database. Resolving this issue is a work in progress. There are a total of 151 cases with a non-optimal solution in the SUT balancing over the time series ( 3 cases for year 2015). Data for these cases are set to zero and sum up to $0.15 \%$ of global GDP through the time series, hence it should not significantly influence the overall results. To resolve the balancing issues would require more detailed and reliable raw data, which again would manifest in the balancing routine deviating less from the initial estimated SUTs.

Setting the unbalanced countries to zero lead to a slight imbalance in land footprint results (see Table 2). This is one of several ways of dealing with such imbalances. In Eora, this has been handled by compiling the unbalanced regions in a Rest-of-the-world region (Lenzen et al. 2013). As setting the values of the environmental extensions matrix (F) to zero for an unbalanced country A means neglecting the land use embodied in imports of a country B from country A, there is a slight underreporting of land use in EXIOBASE 3rx. In 2015, Puerto Rico and the Dominican Republic are the countries whose total land footprints are affected the most by this, with an underreported footprint of $0.86 \%$. For the aggregated database this effect has different distributional impacts as it affects all countries that import from the RoW region that country A is aggregated to. In addition, it affects the domestic part of the RoW region's footprint as there is not a one-to-one relationship between the output of country $\mathrm{A}$ and the land use per unit of output $(\mathbf{S})$. RoW America's land footprint is affected heaviest by this with a change of $0.25 \%$. In the 49-region version of EXIOBASE 3rx, the change is largest in Latvia (0.08\%). Resolving the issue with unbalanced regions in EXIOBASE 3rx is a work in progress.

Using the EEBT approach, we do not distinguish between intermediate and final use of traded products. The approach fits with the scope of this paper as we look at the land embodied in aggregated imports and exports. The EEBT approach is also argued to be more relevant for global trade-related policy (Peters 2007). However, when allocating impacts to categories of final demand, the EEBT approach will give different results compared to the Leontief approach due to different allocation of impacts, although the global total impact is the same. For a country, imported goods that are used for intermediate production, and later exported are in the EEBT approach accounted as part of the imported footprint, while in the MRIO approach, they are not. The implications of this are discussed in Peters (2007). The extent of the difference between the two approaches 
is unexplored in this paper, although previous studies indicate that this difference could be significant ( $\mathrm{Su}$ and Ang 2011).

In terms of land use data, other types of area use such as ocean are sometimes included in land use studies (e.g., Weinzettel et al. (2013)). This could alter the regional results, the land embodied in trade, and most likely the hotspots for large aggregation errors, through, e.g. consumption of fish (Weinzettel et al. 2013). It is important to be aware that the effects due to regional aggregation are sensitive to the types of land included in the study. Similarly, the picture would likely look different in terms of regions and sectors sensitive to aggregation errors when studying other types of environmental impacts. For example de Koning et al. (2015) found that regional aggregation had small effects on overall carbon and material footprints. Bouwmeester and Oosterhaven (2013) on the other hand find large, and what they refer to as unacceptable aggregation errors for particularly water use, but also for $\mathrm{CO}_{2}$ emissions, although their regional aggregation is more drastic with aggregating 43 regions to five and two regions. The deviating conclusions on the effect of regional aggregation in other papers suggest that there is still need for further research on both the underlying causes of differences in these results, as well as identifying regions that are sensitive to aggregation errors. Although de Koning et al. (2015) look at different indicators, our findings coincide in the sense that when looking at the footprint of a country, the net effect of a regional aggregation is not drastic, but when exploring products traded and trade partners in more detail we find large effects of aggregation. This could also manifest in larger deviations when aggregating to very few regions, as in Bouwmeester and Oosterhaven (2013).

\subsection{Further work}

The results at hand are the first published results using EXIOBASE 3rx. We restrict our scope to the effect of regional aggregation of land use embodied in trade. However, with the limitations related to the EEBT approach and unbalanced countries in mind, there is still unexplored potential in using the database for land use studies in its current form. Firstly, there are multiple land use extensions available, which allows for studying different land types embodied in trade. Secondly, land use embodied in trade can be studied on a sectoral level as the database includes 200 products harmonized across all regions. Thirdly, the database is a time series from 1995 to 2015 which allows for studying the drivers of land use in form of panel regressions or similar methods. This creates opportunities for following up literature findings that suggest some degree of correlation between income and land use (Weinzettel et al. 2013; Ivanova et al. 2016). Panel regression studies using MRIO time series data also enable predictions into the future, which could help overcome the retrospective scope that is identified as a limitation of MRIO studies, which again could increase policy relevance (Axtell et al. 2001).

Currently only land extensions are processed for EXIOBASE 3rx. However, adding other environmental extensions to the database is a work in progress. More immediately, we chose land use as it is a simple and key indicator of agricultural related impacts. The application of biodiversity characterization factors (Verones et al. 2017) and net-primary productivity (Kastner et al. 2015; Weinzettel et al. 2019) are simple extensions to obtain more policy-relevant work. Furthermore, the correlation (Silva Simas et al. 2017) of land 
use with other agricultural impacts such as blue water consumption (Lutter et al. 2016) and eutrophication (Hamilton et al. 2018) gives a good basis for further extension.

Regarding resolution, the sectoral resolution in EXIOBASE is one of the most detailed in the available MRIOs (Steen-Olsen et al. 2014). However, despite the comparably high sectoral resolution of EXIOBASE 3rx, the sectoral resolution is a main point of criticism and source of error of land use studies using MRIO (Bruckner et al. 2015; Weinzettel et al. 2013; Steen-Olsen et al. 2012). Disaggregation of sectors is argued by Weinzettel et al. (2014) to be an important future development of MRIOs, and can replace the hybrid approaches applied to overcome this limitation today. Already we are seeing the linking of detailed FAO production and use data to both aggregated and disaggregated MRIO tables (Weinzettel et al. 2019) and even the construction of country-specific physical input-output tables (Bruckner et al. 2019).

In terms of methods, there is further work on expanding the cross-entropy model (Többen and Schröder 2018) used for reconciling the bilateral trade data with main aggregates of national accounts and estimates of product output, first, to the balancing of the SUTs and, later, to the simultaneous reconciliation of bilateral trade, SUTs and the physical extensions. The main challenges for the practical implementation of such a concept are the computational requirements due to the enormous size of the database (see the method section for a brief overview of the size of EXIOBASE 3rx). However, recent theoretical work on topological transformations (Rodrigues et al. 2016) and maximum entropy models to reconcile data in physical and monetary units simultaneously (Többen 2017) constitute first theoretical steps to solve this issue.

\section{Conclusion}

With divergence in environmental results between MRIOs hampering the policy relevance of MRIO studies, it is important to both develop more detailed models, and to get a systematic understanding about the underlying sources of these differences. We have developed a regional extension of EXIOBASE 3 called EXIOBASE 3rx and studied the effect of regional aggregation on land use embodied in trade by comparing results to an aggregated version of the same database consisting of 49 regions. Whilst the disaggregated database is experimental in that a lot of structural economic data are estimated, country-specific data on agricultural and resource output, as well as trade are included. We find that the regional aggregation error for land use embodied in imports on a sectoral level is highly concentrated on sectors with high biomass demand, such as forestry, meat from animals, wood products and hotels and restaurant services. The effect on regions shows that the balance of land embodied in trade differs with up to $6 \%$ between the aggregate database and EXIOBASE 3rx, while the net aggregation error of land embodied in imports for some of the 49 EXIOBASE regions differ up to $68 \%$ between the databases. The largest absolute aggregation errors for land embodied in imports are found for Asian imports particularly originating in RoW Asia and RoW Africa.

Our findings have two important implications regarding the use of MRIOs for land use studies. Firstly, regions in Asia and Africa should be represented in detail, and higher sectoral disaggregation is necessary for a handful of key sectors. Secondly, we suggest that MRIO developers are aware of the potentially significant effects of regional 
aggregation and build MRIOs that find the right balance between number of regions and sectors for their studies, while at the same time acknowledging the potential uncertainty introduced by assumptions aimed at closing data gaps in raw data. Further research is needed to identify key sectors and regions vulnerable to aggregation errors. If these are found to converge across environmental and socioeconomic extensions, MRIO systems can be built that find the right level of detail without becoming unnecessarily large. We believe that this is an important step in finding the sources of intra-MRIO result discrepancies and could increase the policy uptake of MRIO studies.

\section{Supplementary information}

Supplementary information accompanies this paper at https://doi.org/10.1186/s40008-020-0182-y.

Additional file 1. Supplementary material.

Additional file 2. Concordance matrices for regions, land use types and industries.

Additional file 3. Land use time series results (1995-2015).

\section{Abbreviations}

EEBT: Emissions embodied in bilateral trade; MRIO: Multiregional input output; RoW: Rest of the world; SUT: Supply-use table.

Acknowledgements

Not applicable.

Authors' contributions

ELB, KS, RW and JT built the database. MT, TK and KHE processed the land use accounts. ELB and KSO adjusted the land use accounts to fit with the database format. ELB and KSW processed land use results. ELB wrote the manuscript with important contributions from all co-authors. All authors read and approved the final manuscript.

\section{Funding}

KHE, TK and MT gratefully acknowledge funding from the projects Cobaluce Deutsche Forschungsgemeinschaft (DFG KA 4815/1-1) and GELUC (Austrian Science Fund P29130).

\section{Availability of data and materials}

The database generated and analyzed during the current study are available in the EXIOBASE 3rx repository, https:// zenodo.org/deposit/2654460.

Most of the raw data used to build EXIOBASE 3rx, as referred to in the manuscript, is publically available at the repositories listed in the list of references.

The land use dataset is available in an aggregate format in the EXIOBASE 3rx repository. The full dataset is available from the corresponding authors (MT, TK and KHE) on reasonable request.

\section{Competing interests}

The authors declare that they have no competing interests.

\section{Author details}

${ }^{1}$ Industrial Ecology Programme, Department of Energy and Process Engineering, Norwegian University of Science and Technology (NTNU), Trondheim, Norway. ${ }^{2}$ Institute of Social Ecology, University of Natural Resources and Life Sciences, Vienna (BOKU), Vienna, Austria. ${ }^{3}$ Senckenberg Biodiversity and Climate Research Centre (SBIK-F), Frankfurt Am Main, Germany. ${ }^{4}$ SINTEF Industry, 7465 Trondheim, Norway.

Received: 30 May 2019 Revised: 2 November 2019 Accepted: 18 January 2020

Published online: 13 February 2020

\section{References}

Aguiar A, Narayanan B, Mcdougall R (2016) An overview of the gtap 9 data base. J Global Econ Anal 1:181-208

Alsamawi A, Murray J, Lenzen M (2014a) The employment footprints of nations. J Ind Ecol 18:59-70

Alsamawi A, Murray J, Lenzen M, Moran D, Kanemoto K (2014b) The inequality footprints of nations: a novel approach to quantitative accounting of income inequality. PLoS ONE 9:e110881

Axtell RL, Andrews CJ, Small MJ (2001) Agent-based modeling and industrial ecology. J Ind Ecol 5:10-13

Bouwmeester MC, Oosterhaven J (2013) Specification and aggregation errors in environmentally extended input-output models. Environ Resour Econ 56:307-335

Bruckner M, Giljum S, Lutz C, Wiebe KS (2012) Materials embodied in international trade-global material extraction and consumption between 1995 and 2005. Global Environ Change 22:568-576 
Bruckner M, Fischer G, Tramberend S, Giljum S (2015) Measuring telecouplings in the global land system: a review and comparative evaluation of land footprint accounting methods. Ecol Econ 114:11-21

Bruckner M, Wood R, Moran D, Kuschnig N, Wieland H, Maus V, Börner J (2019) FABIO—-the construction of the food and agriculture biomass input-output model. Environ Sci Technol 53:11302-11312

de Koning A, Bruckner M, Lutter S, Wood R, Stadler K, Tukker A (2015) Effect of aggregation and disaggregation on embodied material use of products in input-output analysis. Ecol Econ 116:289-299

Edens B, Hoekstra R, Zult D, Lemmers O, Wilting H, Wu R (2015) A method to create carbon footprint estimates consistent with national accounts. Econ Syst Res 27:1-18

Erb K-H, Gaube V, Krausmann F, Plutzar C, Bondeau A, Haberl H (2007) A comprehensive global 5 min resolution land-use data set for the year 2000 consistent with national census data. J Land Use Sci 2:191-224

Eurostat (2008) https://ec.europa.eu/eurostat/web/products-manuals-and-guidelines/-/KS-RA-07-013. EUROSTAT. https ://ec.europa.eu/eurostat/web/products-manuals-and-guidelines/-/KS-RA-07-013. Accessed 27 Sept 2018

FAOSTAT (2014) FAOSTAT_Prodstat; Food and Agriculture Organization of the United Nations. FAO Statistics Division. http://faostat.fao.org/site/567/DesktopDefault.aspx\#ancor. Accessed 25 Feb 2016

FAOSTAT (2019) FAOSTAT_land use. http://www.fao.org/faostat/en/\#data/RL. Accessed 9 Jan 2019

Gaulier G, Zignago S (2010) Baci: international trade database at the product-level (the 1994-2007 version)

Gibbons JC, Wolsky AM, Tolley G (1982) Approximate aggregation and error in input-output models. Resour Energy 4:203-230

Giljum S, Wieland H, Lutter S, Eisenmenger N, Schandl H, Owen A (2019) The impacts of data deviations between MRIO models on material footprints: a comparison of EXIOBASE, Eora, and ICIO. J Ind Ecol 23(4):946-958

Golan A, Vogel SJ (2000) Estimation of non-stationary social accounting matrix coefficients with supply-side information. Econ Syst Res 12:447-471

Hambÿe C, Hertveldt B, Michel B (2018) Does consistency with detailed national data matter for calculating carbon footprints with global multi-regional input-output tables? A comparative analysis for Belgium based on a structural decomposition. J Econ Struct 7:11

Hamilton HA, Ivanova D, Stadler K, Merciai S, Schmidt J, Zelm VAN, Moran D, Wood R (2018) Trade and the role of nonfood commodities for global eutrophication. Nat Sustain 1:314-321

Hubacek K, Feng K (2016) Comparing apples and oranges: some confusion about using and interpreting physical trade matrices versus multi-regional input-output analysis. Land Use Policy 50:194-201

IEA (2015) IEA Energy Balances. International Energy Agency/OECD. http://data.iea.org/. Accessed

Imbeault-Tétreault H, Jolliet O, Deschênes L, Rosenbaum RK (2013) Analytical propagation of uncertainty in life cycle assessment using matrix formulation. J Ind Ecol 17:485-492

International Energy Agency (2018) IEA Data Services. International Energy Agency. http://data.iea.org/. Accessed 24 Sept 2018

Ivanova D, Stadler K, Steen-Olsen K, Wood R, Vita G, Tukker A, Hertwich EG (2016) Environmental impact assessment of household consumption. J Ind Ecol 20:526-536

Jansen PK, Raa TT (1990) The choice of model in the construction of input-output coefficients matrices. Int Econ Rev 31:213-227

Karstensen J, Peters GP, Andrew RM (2015) Uncertainty in temperature response of current consumption-based emissions estimates. Earth Syst Dynam 6:287-309

Kastner T, Schaffartzik A, Eisenmenger N, Erb K-H, Haberl H, Krausmann F (2014) Cropland area embodied in international trade: contradictory results from different approaches. Ecol Econ 104:140-144

Kastner T, Erb K-H, Haberl H (2015) Global human appropriation of net primary production for biomass consumption in the European Union, 1986-2007. J Ind Ecol 19:825-836

Kazama JI, Tsujii JI (2005) Maximum entropy models with inequality constraints: a case study on text categorization. Mach Learn 60:159-194

Kullback S, Leibler RA (1951) On information and sufficiency. Ann Math Stat 22:79-86

Lenzen M (2011) Aggregation versus disaggregation in input-output analysis of the environment. Econ Syst Res 23:73-89

Lenzen M, Wood R, Wiedmann T (2010) Uncertainty analysis for multi-region input_output models—a case study of the UK'S carbon footprint. Econ Syst Res 22:43-63

Lenzen M, Moran D, Kanemoto K, Foran B, Lobefaro L, Geschke A (2012) International trade drives biodiversity threats in developing nations. Nature 486:109

Lenzen M, Moran D, Kanemoto K, Geschke A (2013) Building eora: a global multi-region input-output database at high country and sector resolution. Econ Syst Res 25:20-49

Leontief WW (1936) Quantitative input and output relations in the economic systems of the United States. Rev Econ Stat 18:105-125

LeontiefW (1970) Environmental repercussions and the economic structure: an input-output approach. Rev Econ Stat $52: 262-271$

Leontief W, Strout A (1963) Multiregional input-output analysis. Structural interdependence and economic development. Springer, Berlin

Lutter S, Pfister S, Giljum S, Wieland H, Mutel C (2016) Spatially explicit assessment of water embodied in European trade: a product-level multi-regional input-output analysis. Global Environ Change 38:171-182

Majeau-Bettez G, Wood R, Strømman AH (2014) Unified theory of allocations and constructs in life cycle assessment and input-output analysis. J Ind Ecol 18:747-770

Marques A, Martins IS, Kastner T, Plutzar C, Theurl MC, Eisenmenger N, Huijbregts MA, Wood R, Stadler K, Bruckner M (2019) Increasing impacts of land use on biodiversity and carbon sequestration driven by population and economic growth. Nat Ecol Evol 3(4):628-637

Miller RE, Blair PD (2009) Input-output analysis: foundations and extensions. Cambridge University Press, Cambridge

Miller RE, Shao G (1990) Spatial and sectoral aggregation in the commodity-industry multiregional input-output model. Environ Plann A 22:1637-1656 
Moran D, Wood R (2014) Convergence between the eora, wiod, exiobase, and openeu's consumption-based carbon accounts. Econ Syst Res 26:245-261

Owen A, Steen-Olsen K, Barrett J, Wiedmann T, Lenzen M (2014) A structural decomposition approach to comparing MRIO databases. Econ Syst Res 26:262-283

Owen A, Wood R, Barrett J, Evans A (2016) Explaining value chain differences in MRIO databases through structural path decomposition. Econ Syst Res 28:243-272

Owen A, Brockway P, Brand-Correa L, Bunse L, Sakai M, Barrett J (2017) Energy consumption-based accounts: a comparison of results using different energy extension vectors. Appl Energy 190:464-473

Palm V, Wood R, Berglund M, Dawkins E, Finnveden G, Schmidt S, Steinbach N (2019) Environmental pressures from Swedish consumption — a hybrid multi-regional input-output approach. J Clean Prod 228:634-644

Peters GP (2007) Opportunities and challenges for environmental MRIO modeling: illustrations with the GTAP database. In: 16th international input-output conference

Peters GP (2008) From production-based to consumption-based national emission inventories. Ecol Econ 65:13-23

Peters GP, Hertwich EG (2008) $\mathrm{CO}_{2}$ embodied in international trade with implications for global climate policy. ACS Publications, Washington, DC

Peters GP, Andrew R, Lennox J (2011) Constructing an environmentally-extended multi-regional input-output table using the GTAP database. Econ Syst Res 23:131-152

Rodrigues J, Marques A, Wood R, Tukker A (2016) A network approach for assembling and linking input-output models. Econ Syst Res 28:518-538

Schaffartzik A, Haberl H, Kastner T, Wiedenhofer D, Eisenmenger N, Erb KH (2015) Trading land: a review of approaches to accounting for upstream land requirements of traded products. J Ind Ecol 19:703-714

Silva Simas M, Pauliuk S, Wood R, Hertwich EG, Stadler K (2017) Correlation between production and consumption-based environmental indicators. The link to affluence and the effect on ranking environmental performance of countries. Ecol Ind 76:317-323

Simas MS, Golsteijn L, Huijbregts MA, Wood R, Hertwich EG (2014) The "bad labor" footprint: quantifying the social impacts of globalization. Sustainability 6:7514-7540

Simoes AJG, Hidalgo CA (2011) The economic complexity observatory: An analytical tool for understanding the dynamics of economic development. In: Workshops at the twenty-fifth AAAI conference on artificial intelligence

Stadler K, Steen-Olsen K, Wood R (2014) The'rest of the world' - estimating the economic structure of missing regions in global multi-regional input-output tables. Econ Syst Res 26:303-326

Stadler K, Wood R, Bulavskaya T, Södersten C-J, Simas M, Schmidt S, Usubiaga A, Acosta-Fernández J, Kuenen J, Bruckner M, Giljum S, Lutter S, Merciai S, Schmidt JH, Theurl MC, Plutzar C, Kastner T, Eisenmenger N, Erb K-H, de Koning A, Tukker A (2018) EXIOBASE 3: developing a time series of detailed environmentally extended multi-regional inputoutput tables. J Ind Ecol 22:502-515

Steen-Olsen K, Weinzettel J, Cranston G, Ercin AE, Hertwich EG (2012) Carbon, land, and water footprint accounts for the European Union: consumption, production, and displacements through international trade. Environ Sci Technol 46:10883-10891

Steen-Olsen K, Owen A, Hertwich EG, Lenzen M (2014) Effects of sector aggregation on $\mathrm{CO}_{2}$ multipliers in multiregional input-output analyses. Econ Syst Res 26:284-302

Su B, Ang BW (2010) Input-output analysis of CO2 emissions embodied in trade: the effects of spatial aggregation. Ecol Econ 70:10-18

Su B, Ang B (2011) Multi-region input-output analysis of $\mathrm{CO}_{2}$ emissions embodied in trade: the feedback effects. Ecol Econ 71:42-53

Su B, Huang HC, Ang BW, Zhou P (2010) Input-output analysis of $\mathrm{CO}_{2}$ emissions embodied in trade: the effects of sector aggregation. Energy Econ 32:166-175

Timmer MP, Dietzenbacher E, Los B, Stehrer R, Vries GJ (2015) An illustrated user guide to the world input-output database: the case of global automotive production. Rev Int Econ 23:575-605

Többen J (2017) On the simultaneous estimation of physical and monetary commodity flows. Econ Syst Res 29:1-24

Többen J, Schröder T (2018) A maximum entropy approach to the estimation of spatially and sectorally disaggregated electricity load curves. Appl Energy 225:797-813

Többen J, Wiebe KS, Verones F, Wood R, Moran DD (2018) A novel maximum entropy approach to hybrid monetaryphysical supply-chain modelling and its application to biodiversity impacts of palm oil embodied in consumption. Environ Res Lett 13:115002

Tukker A, Dietzenbacher E (2013) Global multiregional input-output frameworks: an introduction and outlook. Econ Syst Res 25:1-19

Tukker A, de Koning A, Wood R, Hawkins T, Lutter S, Acosta J, Rueda Cantuche JM, Bouwmeester M, Oosterhaven J, Drosdowski T (2013) EXIOPOL-development and illustrative analyses of a detailed global MR EE SUT/IOT. Econ Syst Res 25:50-70

United Nations (2018a) National Accounts Main Aggregates Database. https://unstats.un.org/unsd/snaama/dnllist.asp. Accessed 24 Sept 2018

United Nations (2018b) UN comtrade Database. United Nations. https://comtrade.un.org/. Accessed 24 Sept 2018

Verones F, Moran D, Stadler K, Kanemoto K, Wood R (2017) Resource footprints and their ecosystem consequences. Sci Rep 7:40743

Weinzettel J, Hertwich EG, Peters GP, Steen-Olsen K, Galli A (2013) Affluence drives the global displacement of land use. Global Environ Change 23:433-438

Weinzettel J, Steen-Olsen K, Hertwich EG, Borucke M, Galli A (2014) Ecological footprint of nations: comparison of process analysis, and standard and hybrid multiregional input-output analysis. Ecol Econ 101:115-126

Weinzettel J, Vačkářu D, Medková H (2019) Potential net primary production footprint of agriculture: a global trade analysis. J Ind Ecol 23:1133-1142 
Wiebe KS, Bruckner M, Giljum S, Lutz C, Polzin C (2012) Carbon and materials embodied in the international trade of emerging economies: a multiregional input-output assessment of trends between 1995 and 2005. J Ind Ecol 16:636-646

Wiebe KS, Harsdorff M, Montt G, Simas MS, Wood R (2019) A global circular economy scenario in a multi-regional inputoutput framework. Environ Sci Technol 53(11):6362-6373

Wiedmann T (2009a) A first empirical comparison of energy footprints embodied in trade—MRIO versus PLUM. Ecol Econ 68:1975-1990

Wiedmann T (2009b) A review of recent multi-region input-output models used for consumption-based emission and resource accounting. Ecol Econ 69:211-222

Wiedmann TO, Schandl H, Lenzen M, Moran D, Suh S, West J, Kanemoto K (2015) The material footprint of nations. Proc Natl Acad Sci 112:6271-6276

Wieland H, Giljum S, Bruckner M, Owen A, Wood R (2018) Structural production layer decomposition: a new method to measure differences between MRIO databases for footprint assessments. Econ Syst Res 30:61-84

Wilting HC, Schipper AM, Bakkenes M, Meijer JR, Huijbregts MA (2017) Quantifying biodiversity losses due to human consumption: a global-scale footprint analysis. Environ Sci Technol 51:3298-3306

Wood R, Hawkins TR, Hertwich EG, Tukker A (2014) Harmonising national input-output tables for consumption-based accounting-experiences from EXIOPOL. Econ Syst Res 26:387-409

Wood R, Stadler K, Bulavskaya T, Lutter S, Giljum S, Koning A, de Kuenen J, Schütz H, Acosta-Fernández J, Usubiaga A Simas M, Ivanova O, Weinzettel J, Schmidt JH, Merciai S, Tukker A (2015) Global sustainability accounting-developing EXIOBASE for multi-regional footprint analysis. Sustainability 7:138-163

Wood R, Moran DD, Rodrigues JFD, Stadler K (2019) Variation in trends of consumption based carbon accounts. Sci Data 6:99

Yamano N, Webb C (2018) Future development of the inter-country input-output (ICIO) database for global value chain (GVC) and environmental analyses. J Ind Ecol 22:487-488

\section{Publisher's Note}

Springer Nature remains neutral with regard to jurisdictional claims in published maps and institutional affiliations.

\section{Submit your manuscript to a SpringerOpen ${ }^{\circ}$ journal and benefit from:}

- Convenient online submission

Rigorous peer review

Open access: articles freely available online

- High visibility within the field

- Retaining the copyright to your article

Submit your next manuscript at $\boldsymbol{\nabla}$ springeropen.com 